\title{
MONITORAMENTO DA TEMPERATURA NO INTERIOR DE CHAPAS AGLOMERADAS DURANTE O PROCESSO DE PRENSAGEM
}

\author{
TEMPERATURE BEHAVIOUR IN PARTICLEBOARD DURING PRESSING
}

\author{
Leandro Calegari ${ }^{1}$ Clovis Roberto Haselein ${ }^{2}$ Cristiano Hack $^{3}$
}

Darci A. Gatto ${ }^{4}$ Marcos V. Barros ${ }^{3}$ Elio José Santini ${ }^{5}$

\section{RESUMO}

O objetivo do presente trabalho foi analisar o comportamento da temperatura nas faces e no miolo de chapas de partículas aglomeradas, coladas com $8 \%$ de adesivo (base peso seco das partículas) taninoformaldeído. As chapas foram produzidas com três repetições por tratamento, com massa específica nominal de $0,7 \mathrm{~g} / \mathrm{cm}^{3}$ e pressão específica de prensagem de $27 \mathrm{kgf} / \mathrm{cm}^{2}$. Os tratamentos basearam-se na utilização de flocos de pinus (Pinus elliottii) e partículas de eucalipto (Eucalytus sp), sendo que os flocos de pinus apresentavam três diferentes comprimentos nominais $(40,75$ e $110 \mathrm{~mm})$ e duas espessuras $(0,5 \mathrm{e} 1,0 \mathrm{~mm})$. Também foram analisados duas temperaturas de prensagem $\left(140\right.$ e $\left.180^{\circ} \mathrm{C}\right)$ e dois teores de umidade nominal do colchão $(17$ e $21 \%)$. A temperatura no interior dos painéis durante a prensagem foi obtida por meio de fios para termopares tipo K (cromo-alumel). Os gráficos da temperatura em função do tempo de prensagem mostraram uma rápida elevação da temperatura nos primeiros 100 segundos de prensagem, mantendo-se num plateau possivelmente após atingir a temperatura de ebulição da água. A temperatura voltou a aumentar, de forma mais gradual, após a perda de grande parte da umidade do colchão. Observa-se que colchões formados por flocos de maior espessura apresentaram elevação mais rápida de temperatura no miolo. O principal fator que influenciou na velocidade de elevação da temperatura no miolo dos painéis aglomerados foi o teor de umidade do colchão, sendo que quanto maior o teor de umidade, mais rápida foi a elevação da temperatura.

Palavras-chave: elevação da temperatura; chapas aglomeradas; tanino-formaldeído.

\section{ABSTRACT}

The objective of the present work was to investigate the behaviour of core and face temperatures of particleboard glued with $8 \%$ tannin-formaldehyde adhesive. The boards were manufactured with three replication per treatment, with density of $0,7 \mathrm{~g} / \mathrm{cm}^{3}$ and $27 \mathrm{kgf} / \mathrm{cm}^{2}$ of pressing specific pressure. Pine flakes (40, 75 and $110 \mathrm{~mm}$ long and 0,5 and $1,0 \mathrm{~mm}$ thick) and eucalypt particles were used and two pressing temperatures $\left(140\right.$ and $\left.180^{\circ} \mathrm{C}\right)$ along with two mat moisture content $(17$ and $21 \%)$ were employed. The curves of temperature rise with pressing time indicated a fast temperature rise during the first 100 seconds of pressing, remaining at a plateau possible after reaching water boiling temperature. The temperature increased again, but on a more gradual form, after the lost mat moisture. It was possible to observe that mat formed by flakes of larger thicknesses showed faster initial temperature rise. The main factor that influenced the temperature behaviour at the board core was the mat moisture content. The higher the mat moisture content, the faster the temperature rise.

Key words: temperature rise; particleboard; tannin-formaldehyde.

1. Engenheiro Florestal, Mestrando pelo Programa de Pós-Graduação em Engenharia Florestal, Centro de Ciências Rurais, Universidade Federal de Santa Maria, CEP 97105-900, Santa Maria (RS). Bolsista do CNPq. leandrocalegari@yahoo.com.br

2. Engenheiro Florestal, PhD., Professor Adjunto do Departamento de Ciências Florestais, Centro de Ciências Rurais, Universidade Federal de Santa Maria, CEP 97105-900, Santa Maria (RS). haseleic@ccr.ufsm.br

3. Engenheiro Florestal, Mestrando pelo Programa de Pós-Graduação em Engenharia Florestal, Centro de Ciências Rurais, Universidade Federal de Santa Maria, CEP 97105-900, Santa Maria (RS).

4. Engenheiro Florestal, MSc., Doutorando pelo Programa de Pós-Graduação em Engenharia Florestal, Centro de Ciências Rurais, Universidade Federal de Santa Maria, CEP 97105-900, Santa Maria (RS).

5. Engenheiro Florestal, Dr., Professor Adjunto do Departamento de Ciências Florestais, Centro de Ciências Rurais, Universidade Federal de Santa Maria, CEP 97105-900, Santa Maria (RS). santinie@ccr.ufsm.br

Recebido para publicação em 18/12/2003 e aceito em 28/03/2005. 


\section{INTRODUÇ̃̃OO}

A prensagem é uma das fases mais importante na fabricação de painéis de madeira. Além de determinar a espessura e a densidade final, ainda transfere o calor, responsável pela cura da resina (adesivo), proporcionando a consolidação do painel. García et al. (2001) descrevem que o calor plasticiza a madeira e polimeriza a resina, enquanto a pressão exercida pelos pratos da prensa junta os flocos, aderindo-os.

O monitoramento da temperatura no interior do colchão de partículas, durante a prensagem, pode contribuir de forma relevante para a otimização efetiva do processo. Esse método de controle pode ser feito on line, fornecendo dados individualizados para cada painel em produção. A heterogeneidade do material empregado para a produção de partículas, causada sobretudo pela obtenção de matérias-primas de diversos fornecedores e da própria madeira, pode ser monitorada por sistema computacional que poderá promover alterações necessárias de acordo com os dados obtidos do colchão. Assim, será possível determinar o tempo de prensagem ideal para cada colchão, já que a temperatura mínima necessária para efetuar a cura do adesivo poderá ser determinada com exatidão. Dessa forma, serão evitados tempos insuficientes de prensagem, o que diminui a qualidade dos painéis em razão da cura incompleta do adesivo, e, por outro lado, um tempo excessivo de prensagem gerando maior consumo de energia e redução na produtividade da indústria.

Nesse contexto, o objetivo do presente trabalho foi analisar o comportamento da temperatura nas faces e no miolo de chapas aglomeradas, coladas com tanino-formaldeído, produzidas sob diferentes parâmetros de produção (geometria dos flocos, tipo de madeira, temperatura de prensagem e teor de umidade do colchão).

\section{REVISÃO BIBLIOGRÁFICA}

A transferência de calor durante o processo de prensagem ocorre pela combinação de três mecanismos básicos (condução, convecção e irradiação), sendo que sua importância varia conforme a fase de prensagem. A condução é o principal modo de transferência de calor, sendo que ocorre por cauda do contato dos pratos da prensa com a superfície do colchão os quais se encontram sob diferentes temperaturas. Zombori (2001) descreve que calor também é gerado pela compressão do colchão e da reação exotérmica de polimeração do adesivo. O calor de compressão e polimeração contribuem com, respectivamente, 2 e $22 \%$ da energia total.

Tanto Zombori (2001) quanto Bolton et al. (1989) subdividiram o comportamento da temperatura em cinco períodos e descreveram as alterações em relação aos planos vertical (paralelo à espessura do painel) e horizontal (perpendicular à espessura).

No primeiro período, Zombori (2001) descreve que não ocorre aumento no centro do colchão. Nas superfícies, a temperatura começa a aumentar rapidamente ao entrar em contato com os pratos aquecidos. Portanto, um grande gradiente de temperatura forma-se na direção vertical, direcionando o calor para o centro por condução. As superfícies do colchão rapidamente alcançam a temperatura de evaporação da água, proporcionando redução do teor de umidade nesse local. Conseqüentemente, no final desse período, forma-se um gradiente de pressão, conduzindo o vapor d'água da superfície para o centro do painel. Durante tal fase, o processo de transporte de massa ocorreu rapidamente em conseqüência da permeabilidade do colchão, proporcionado pelos espaços vazios.

No segundo período, o aumento do gradiente de pressão de vapor iniciado no período anterior intensifica-se, causando aumento da temperatura e pressão no centro do colchão (Bolton et al.,1989). Na direção vertical, os processos de transferência de calor e massa aceleraram-se. Os gradientes de pressão e temperatura promovem maior transferência de calor (Zombori, 2001).

No terceiro período, Bolton et al. (1989) descrevem que ocorre progressiva redução no aumento da temperatura no centro do painel. Esse comportamento se deve à redução da taxa de transferência de energia a qual é atribuída à combinação dos seguintes fatores: aumento na perda de vapor por causa do aumento da pressão interna; redução do gradiente de temperatura entre o centro e a superfície; diminuição no calor latente no centro do painel em função do aumento do teor de umidade e aumento do calor latente próximo às superfícies em função da queda do teor de umidade. Esse último fator proporciona redução da quantidade de vapor produzido por unidade de energia proveniente dos pratos aquecidos da prensa. 
Zombori (2001), durante esta fase, observou que a temperatura se manteve em torno de 110 a $118^{\circ} \mathrm{C}$, até o final do período. Na direção horizontal, um pequeno gradiente de temperatura (aproximadamente $5^{\circ} \mathrm{C}$ ) formou-se entre o centro e a borda do painel, favorecendo a transferência de calor para o ambiente. $\mathrm{O}$ mesmo comportamento foi observado para a pressão.

No quarto período, não ocorre aumento da temperatura no centro do painel (Zombori, 2001), sendo denominado de plateau (Bolton et al., 1989 e García et al. 2001). A taxa de produção de vapor das camadas mais próximas dos pratos tornam-se menores que as perdas para o ambiente. Conseqüentemente, a pressão declinou (Bolton et al, 1989).

O quinto período caracteriza-se pelo pequeno aumento da temperatura no centro do painel. Ocorreu declínio do teor de umidade em praticamente todo o colchão. Na direção vertical, o calor continuou a ser transportado dos pratos para o centro (condução). Ocorreu pequeno gradiente de pressão. Na direção horizontal, ainda ocorreu gradiente de vapor entre o centro e a borda do painel, reduzindo continuamente o teor de umidade da manta (Zombori, 2001).

Wilcox (1953) analisou a elevação da temperatura no miolo de chapas duras produzidas com base em fibras de Douglas-fir (Pseudotsuga menziesii) quando produzidas sob diferentes temperaturas, pressões e tempos de prensagem. A análise foi realizada pelo método de prensagem em três estágios. Esse método consiste da aplicação de uma breve pressão inicial no colchão, a alta temperatura, seguida de uma breve abertura dos pratos da prensa, permitindo a liberação do vapor produzido. Posteriormente, uma segunda prensagem é novamente aplicada até que ocorra a consolidação do painel. Quando comparada com a prensagem convencional, a prensagem em três estágios apresenta menor risco de ocorrência do estouro do painel, pela saída mais fácil do vapor durante o processo de prensagem. Concluiu descrevendo que, entre as variáveis analisadas, o aumento da temperatura de prensagem se destacou por proporcionar redução do tempo de prensagem e melhora das propriedades físico-mecânicas.

Pichelin et al. (2001) e Calegari et al. (2000) descreveram o perfil da temperatura de modo semelhante a Zombori (2001) e Bolton et al.(1989). Pichelin et al. (2001), entretanto, descreveram que, quando o colchão é prensado sob alto teor de umidade (20 a 24\%), o perfil da temperatura tende a se comportar de maneira diferenciada de algumas fases descritas por Zombori (2001). Na segunda fase, não ocorre elevação linear da temperatura, mas, sim, um rápido aumento no início da fase e, posteriormente, um aumento muito mais gradativo. Na quinta fase, de modo contrário que foi observado em colchões de baixo teor de umidade, a temperatura continua a declinar possivelmente em conseqüência da manutenção da umidade no centro.

Steffen et al. (1999), realizando simulações em colchões de MDF (Medium Density Fiberboard), não observaram interrupção do aumento da temperatura quando esta alcançou $100^{\circ} \mathrm{C}$ no centro do colchão. Entretanto, estabilizou em aproximadamente $110^{\circ} \mathrm{C}$, indicando a temperatura de ebulição da mistura dos líquidos presentes no centro do colchão. Albuquerque (2003) descreveu que testes indicaram que, após o miolo do painel atingir $95^{\circ} \mathrm{C}, 2$ minutos de prensagem foram suficientes para o painel atingir uma boa consolidação.

$\mathrm{O}$ aumento do teor de umidade influi diretamente sobre a taxa de transferência de calor, da superfície para o centro do colchão (Eleotério, 2000 e Pichelin et al.,2001). Pichelin et al.(2001) descreveram também sobre a importância da temperatura de prensagem. Quanto maior esse parâmetro, mais rápido é a condução de calor, conseqüência do maior gradiente de vapor e calor pelo colchão. Entretanto, Wilcox (1953), utilizando uma temperatura de prensagem de $240^{\circ} \mathrm{C}$, notou considerável declínio do módulo de ruptura (MOR) dos painéis, conseqüência da degradação da estrutura cristalina da cadeia celulósica. Segundo Suleiman et al. (1999), além da mudança do comportamento físico, temperaturas demasiadamente elevadas afetam a capacidade de condução de calor. Descreveram ainda que a densidade é o principal fator que influi na condutividade térmica da madeira.

Eleotério (2000) descreve que o aumento da umidade do colchão proporciona redução da pressão específica necessária, uma vez que a umidade se vaporiza durante a prensagem a quente, tornando plásticas as fibras. Como desvantagem do alto teor de umidade, cita o aumento do tempo de prensagem, tempo esse necessário para a retirada da umidade existente no painel. Segundo Calegari et al. (2000), se o processo de 
prensagem for interrompido antes da evaporação de boa parte da umidade presente no interior do colchão, a pressão de vapor d'água pode proporcionar explosões, deteriorando o painel. Esse é um problema sério para a prensagem com altos teores de umidade, como é o caso dos realizados com adesivos à base de taninoformaldeído. As altas temperaturas requeridas para a cura dos adesivos termofixos utilizados atualmente contribuem para esse problema.

García et al. (2001) comentaram e ilustraram em forma de gráficos o efeito do alinhamento dos flocos e da densidade sobre a transferência de calor e vapor durante a prensagem de colchões de OSB (Oriented Strand Boards). Nenhum tipo de adesivo foi utilizado. Notaram que o efeito do alinhamento dos flocos foi mais significativo em colchões de maior densidade. Os colchões formados por flocos orientados ao acaso demonstraram maior pressão interna. Esse comportamento se deve, possivelmente, ao fato de que o alinhamento ao acaso ter permeabilidade inferior ao colchão com flocos alinhados, dificultando a saída do gás pelas bordas. $\mathrm{O}$ efeito da pressão interna de gás e permeabilidade lateral sobre a temperatura apareceram no plateau. $\mathrm{O}$ aumento da pressão, em conseqüência da vaporização da umidade, limita o aumento da temperatura, resultando em pequeno ou nenhum aumento dessa. Entretanto, a menor temperatura de plateau $\left(105\right.$ a $\left.115^{\circ} \mathrm{C}\right)$ nos painéis de menor densidade pode ser atribuída à menor pressão de gás. De modo semelhante, uma maior pressão nos painéis formados por flocos alinhados ao acaso resulta em maior temperatura de plateau $\left(130\right.$ a $\left.140^{\circ} \mathrm{C}\right)$.

A taxa de transferência de calor das faces para o centro do painel é responsável pela formação de um perfil de densidade. Nos primeiros instantes de prensagem, ocorre a formação de vapor primeiramente nas faces do colchão, plastilizando a lignina da madeira e facilitando sua compressão. Enquanto isso, o centro do painel encontra-se frio, resistindo à compressão. Quando o centro atinge a temperatura que permitiria uma maior compactação, o painel já atingiu a espessura desejada, não sendo mais compactado. Isso proporciona a formação de painéis com maior densidade nas faces do que no centro (Eleotério, 2000).

\section{MATERIAIS E MÉTODOS}

O presente estudo foi conduzido no Laboratório de Produtos Florestais, pertencente à Universidade Federal de Santa Maria (UFSM), RS. Madeira de duas espécies florestais foram utilizadas para a confecção das chapas aglomeradas: pinus (Pinus elliottii Engelm.) e eucalipto (Eucalyptus sp).

A madeira de pinus foi obtida de três árvores de 25 anos de idade, selecionadas ao acaso de um povoamento localizado na UFSM. De cada árvore, foram retiradas as duas primeiras toras de $2,5 \mathrm{~m}$. Discos foram retirados para a determinação da massa específica básica (peso seco/volume saturado). Na marcenaria da UFSM, as toras foram transformadas em tábuas de espessura nominal igual a $20 \mathrm{~mm}$. Em seguida, foram seccionadas, em seu sentido transversal, gerando baguetas de três diferentes larguras nominais: 110, 75 e 40 $\mathrm{mm}$. Após essas baguetas estarem saturadas em água e aquecidas a $50^{\circ} \mathrm{C}$, foram transformadas em flocos com espessuras nominais de 0,5 e 1,0 mm no gerador de partículas de laboratório.

Desse modo, a madeira de pinus foi transformada em flocos de três diferentes comprimentos (determinada pela largura das baguetas), duas diferentes espessuras e largura constante (determinada pela espessura das tábuas). Posteriormente, os flocos foram secados ao ar e armazenados em sacos de polietileno.

Partículas industriais de eucalipto foram obtidas da empresa SETA S.A., localizada em Estância Velha, RS, as quais apresentavam dimensões diferenciadas das obtidas do pinus. As partículas de eucalipto apresentavam geometria aproximadamente cilíndrica, com comprimento e diâmetro médios reais de 24,0 e $1,1 \mathrm{~mm}$ respectivamente.

Este estudo se baseou em dois experimentos. No primeiro experimento, analisou-se a influência da geometria dos flocos de pinus. Utilizaram-se flocos com duas espessuras nominais $(0,5$ e $1,0 \mathrm{~mm})$ e três larguras nominais $(110,75$ e $40 \mathrm{~mm}$ ). Já no segundo, analisaram-se dois tipos de partículas (flocos de pinus e partículas de eucalipto), duas temperaturas de prensagem $\left(140\right.$ e $\left.180^{\circ} \mathrm{C}\right)$ e dois teores de umidade nominais do colchão $(17$ e $21 \%)$. Ambos os experimentos se basearam no delineamento fatorial. Os tratamentos investigados são caracterizados na Tabela 1 , sendo que o primeiro experimento corresponde aos tratamentos 1 ao 6 e o segundo, dos tratamentos 6 ao 13 . 
TABELA 1: Relação dos tratamentos utilizados na confecção das chapas.

TABLE 1: Treatments used for board manufacturing.

\begin{tabular}{|c|c|c|c|c|c|c|c|}
\hline \multirow{3}{*}{$\begin{array}{l}\text { Trata- } \\
\text { mento }\end{array}$} & \multicolumn{5}{|c|}{ Partículas } & \multirow{3}{*}{$\begin{array}{c}\text { Temperatura } \\
\text { de prensagem } \\
\left({ }^{\circ} \mathrm{C}\right)\end{array}$} & \multirow{3}{*}{$\begin{array}{c}\mathrm{Tu} \\
\text { nominal }^{2} \\
(\%)\end{array}$} \\
\hline & \multirow[t]{2}{*}{ Tipo } & \multicolumn{4}{|c|}{ Dimensões $^{1}(\mathrm{~mm})$} & & \\
\hline & & $\mathrm{L}$ & $\mathrm{E}$ & $\mathrm{C}$ & Diâmetro & & \\
\hline 1 & flocos de pinus & 20,0 & 1,0 & 40,0 & -- & 180 & 17,0 \\
\hline 2 & flocos de pinus & 20,0 & 0,5 & 40,0 & -- & 180 & 17,0 \\
\hline 3 & flocos de pinus & 20,0 & 1,0 & 75,0 & -- & 180 & 17,0 \\
\hline 4 & flocos de pinus & 20,0 & 0,5 & 75,0 & -- & 180 & 17,0 \\
\hline 5 & flocos de pinus & 20,0 & 1,0 & 110,0 & -- & 180 & 17,0 \\
\hline 6 & flocos de pinus & 20,0 & 0,5 & 110,0 & -- & 180 & 17,0 \\
\hline 7 & flocos de pinus & 20,0 & 0,5 & 110,0 & -- & 180 & 21,0 \\
\hline 8 & flocos de pinus & 20,0 & 0,5 & 110,0 & -- & 140 & 17,0 \\
\hline 9 & flocos de pinus & 20,0 & 0,5 & 110,0 & -- & 140 & 21,0 \\
\hline 10 & partículas de eucalipto & -- & -- & 24,0 & 1,1 & 180 & 17,0 \\
\hline 11 & partículas de eucalipto & -- & -- & 24,0 & 1,1 & 180 & 21,0 \\
\hline 12 & partículas de eucalipto & -- & -- & 24,0 & 1,1 & 140 & 17,0 \\
\hline 13 & partículas de eucalipto & -- & -- & 24,0 & 1,1 & 140 & 21,0 \\
\hline
\end{tabular}

Em que: 1 = para os flocos de pinus correspondem às dimensões nominais, enquanto que para as partículas de eucalipto, corresponde às dimensões reais (valor médio de 100 partículas); $2=$ Teor de umidade nominal dos colchões (base úmida); $\mathrm{L}=$ largura; $\mathrm{E}=$ espessura; $\mathrm{C}=$ comprimento.

Aproximadamente 12 horas antes de sua utilização, ambos os tipos de partículas foram colocados em estufa com circulação forçada de ar, a $60^{\circ} \mathrm{C}$, condições essas que proporcionaram uma umidade de equilíbrio de, aproximadamente, $3 \%$ (base seca).

As chapas foram produzidas aleatoriamente, com três repetições por tratamentos analisados. Utilizou-se massa específica nominal de $0,7 \mathrm{~g} / \mathrm{cm}^{3}$ (peso seco/volume ao teor de umidade de equilíbrio).

O adesivo utilizado foi à base de tanino-formaldeído, na proporção 10:1 respectivamente (partes por peso de sólidos não-voláteis), com viscosidade inferior a $200 \mathrm{mPa}$. O tanino, também obtido da empresa SETA S.A., possuía um teor de sólido de $37 \%$ e teve seu $\mathrm{pH}$ corrigido para $8,0 \mathrm{com}$ o uso de hidróxido de sódio. O formaldeído utilizado, por sua vez, apresentava $40 \%$ de sólido. Os teores de parafina (emulsão com $52 \%$ de sólidos) e adesivo foram mantidos constantes, utilizando-se 1 e $8 \%$, respectivamente, baseando-se no peso seco das partículas.

Os materiais utilizados foram misturados com o auxílio de um tambor de laboratório dotado de uma pistola acionada por ar comprimido a qual proporcionou uma vazão de aproximadamente $50 \mathrm{~g} / \mathrm{min}$ de adesivo. Após a mistura, para cada chapa confeccionada, retiraram-se do tambor rotativo três amostras de partículas para a determinação do teor de umidade real médio.

A mistura foi espalhada manualmente em um caixa de madeira de fundo falso e sem tampa, com dimensões $40 \times 40 \times 20 \mathrm{~cm}$, colocada sobre uma chapa de aço galvanizada com 1,0 mm de espessura e revestida com papel vegetal. As partículas caíram por gravidade e foram orientadas ao acaso. Posteriormente, sofreram pré-prensagem à temperatura ambiente durante um período aproximado de 2 minutos.

A prensagem definitiva do colchão foi feita em uma prensa hidráulica durante 10 minutos, com pressão específica de $27 \mathrm{kgf} / \mathrm{cm}^{2}$. A espessura final das chapas aglomeradas foi determinada em 9,5 $\mathrm{mm}$, por meio do uso de duas barras de aço dessa espessura colocadas em lados opostos do colchão as quais limitavam o fechamento total da prensa. O tempo de fechamento total da prensa (até atingir as barras) foi de aproximadamente 40 segundos.

A determinação da elevação da temperatura no interior e nas faces das chapas foram feitas com fios para termopares tipo K (cromo-alumel), revestidos e isolados com fibra de vidro, com espessura de 200 micrômetros, os quais foram inseridos nos colchões durante a fase de montagem no molde de madeira. Em todos os colchões, dois cabos foram inseridos no miolo, correspondendo à metade da espessura. Já o comportamento da temperatura nas faces foi avaliado utilizando-se apenas um cabo termopar para cada face. Deu-se preferência para a temperatura no miolo das chapas uma vez que a cura completa do adesivo ocorre 
após certo período em que a temperatura neste local atinge a temperatura requerida.

Os termopares, conectados a uma placa de aquisição de dados, foram utilizados conforme Klopfenstein Jr. (1997) e Calegari et al. (2000).

Determinou-se a elevação da temperatura no centro do painel pela média aritmética dos dados obtidos pelos dois cabos termopares inseridos neste local. Os dados obtidos nas faces foram analisados de modo semelhante. Porém, como apenas um fio foi utilizado em cada face, não foi realizada média aritmética.

\section{RESULTADOS E DISCUSSÃO}

A madeira de pinus apresentou massa específica básica de $0,48 \mathrm{~g} / \mathrm{cm}^{3}$ e as tábuas, espessura real média de 19,1 mm. As baguetas apresentaram larguras reais médias de 38,3; 75,6 e 117,0 mm, correspondendo ao comprimento dos flocos de pinus.

As espessuras reais médias dos flocos coincidiram com os valores nominais requeridos. Entretanto, ocorreu grande variação entre eles, uma vez que, para a mesma regulagem das facas, os flocos apresentaram diferentes espessuras, dependendo do comprimento da partícula e pressão exercida sobre as baguetas durante sua introdução no gerador.

O principal problema verificado durante a fabricação das chapas foi o controle do teor de umidade do colchão. Durante a mistura dos componentes formadores do colchão no tambor rotativo, observou-se que, aplicando quantidades iguais desses componentes, ocorreu variação do teor de umidade por causa dos diferentes volumes proporcionados pelas partículas. Colchões de menores volumes proporciona redução da área de recebimento dos componentes em emulsão (tanino-formaldeído, parafina e água), aumentando as perdas, uma vez que considerável percentagem desses componentes ficam aderidos no fundo do tambor. Por tentativas, procurou-se corrigir o peso dos componentes em emulsão, conseguindo-se homogeneizar o teor de umidade para a maioria dos colchões. Os valores reais médios das partículas utilizadas e do teor de umidade dos colchões com relação aos tratamentos são apresentados na Tabela 2.

TABELA 2: Valores médios das dimensões das partículas, temperatura de prensagem e teor de umidade para os tratamentos.

TABLE 2: Average size of the particles, pressing temperatures and mattresses moisture content used as a function of the treatments.

\begin{tabular}{|c|c|c|c|c|c|c|c|c|}
\hline \multirow{3}{*}{$\begin{array}{l}\text { Trata- } \\
\text { mento }\end{array}$} & \multicolumn{5}{|c|}{ Partículas } & \multirow{3}{*}{$\begin{array}{c}\text { Temperatura } \\
\text { de prensagem } \\
\left({ }^{\circ} \mathrm{C}\right)\end{array}$} & \multicolumn{2}{|c|}{ Tu real ${ }^{2}$} \\
\hline & \multirow[t]{2}{*}{ Tipo } & \multicolumn{4}{|c|}{ Dimensões $^{1}(\mathrm{~mm})$} & & & \\
\hline & & $\mathrm{L}$ & $\mathrm{E}$ & $\mathrm{C}$ & Diâmetro & & \multicolumn{2}{|c|}{$(\%)$} \\
\hline 1 & flocos de pinus & 19,1 & 1,0 & 38,3 & -- & 180 & 16,8 & $a b$ \\
\hline 2 & flocos de pinus & 19,1 & 0,5 & 38,3 & -- & 180 & 16,7 & $\mathrm{ab}$ \\
\hline 3 & flocos de pinus & 19,1 & 1,0 & 75,6 & -- & 180 & 16,6 & $\mathrm{ab}$ \\
\hline 4 & flocos de pinus & 19,1 & 0,5 & 75,6 & -- & 180 & 16,7 & $\mathrm{ab}$ \\
\hline 5 & flocos de pinus & 19,1 & 1,0 & 117,0 & -- & 180 & 16,8 & $\mathrm{ab}$ \\
\hline 6 & flocos de pinus & 19,1 & 0,5 & 117,0 & -- & 180 & 17,4 & $\mathrm{~b}$ \\
\hline 7 & flocos de pinus & 19,1 & 0,5 & 117,0 & -- & 180 & 21,5 & $\mathrm{c}$ \\
\hline 8 & flocos de pinus & 19,1 & 0,5 & 117,0 & -- & 140 & 16,0 & $a b$ \\
\hline 9 & flocos de pinus & 19,1 & 0,5 & 117,0 & -- & 140 & 20,1 & $\mathrm{c}$ \\
\hline 10 & partículas de eucalipto & -- & -- & 24,0 & 1,1 & 180 & 17,1 & $a b$ \\
\hline 11 & partículas de eucalipto & -- & -- & 24,0 & 1,1 & 180 & 20,0 & $\mathrm{c}$ \\
\hline 12 & partículas de eucalipto & -- & -- & 24,0 & 1,1 & 140 & 15,6 & $\mathrm{a}$ \\
\hline 13 & partículas de eucalipto & -- & -- & 24,0 & 1,1 & 140 & 21,5 & $\mathrm{c}$ \\
\hline
\end{tabular}

Em que: 1 = Valores reais médios de aproximadamente 100 partículas; $\mathrm{L}=$ largura; $\mathrm{E}=$ espessura; $\mathrm{C}=$ comprimento; 2 $=$ Teor de umidade real médio dos colchões (base úmida). Valores seguidos pela mesma letra não diferem estatisticamente, ao nível de 5\% de probabilidade, pelo teste Least Significant Difference (LSD) de Fisher. 


\section{Comportamento geral da elevação da temperatura}

O perfil da elevação da temperatura observado no miolo e nas faces (superior e inferior) das chapas aglomeradas (Figura 1) foi típico para painéis de madeira aglomerada, conforme anteriormente descrito por Bolton et al. (1989), Zombori (2001) e Calegari et al. (2000).

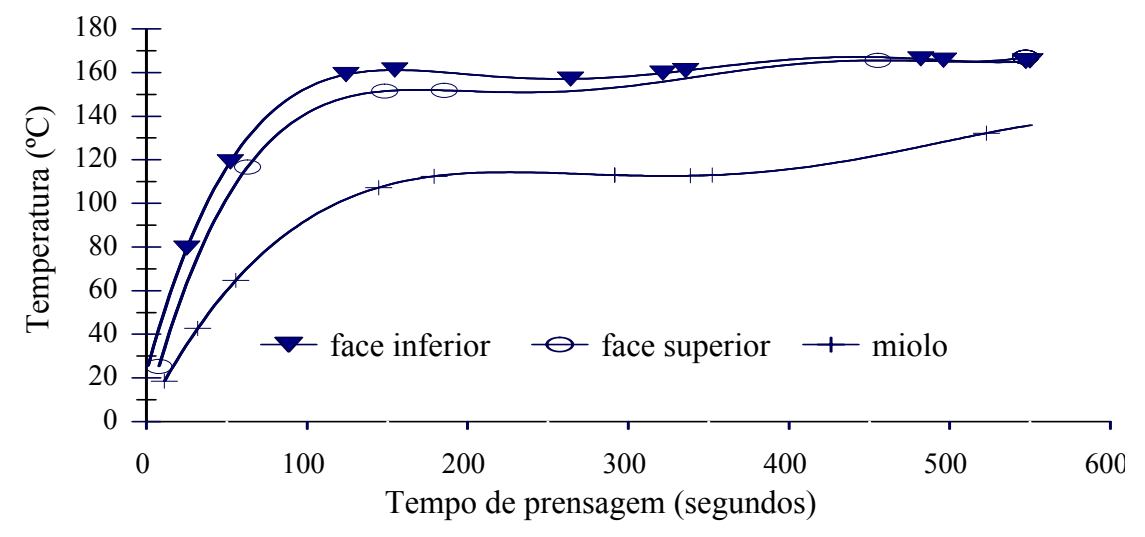

FIGURA 1: Elevação da temperatura em relação ao tempo de prensagem nas diferentes posições das chapas aglomeradas (tratamento 1).

FIGURE 1: Temperature rise with pressing time at different position in the boards (treatment 1).

Observou-se rápido aumento da temperatura durante os primeiros minutos de prensagem, tanto nas faces quanto no miolo. As faces atingiram temperatura superior a $100^{\circ} \mathrm{C}$ anteriormente que no centro, tornando-se aproximadamente constante. Posteriormente, tenderam a atingir a temperatura dos pratos da prensa. Nota-se que a temperatura na face inferior elevou-se mais rapidamente que na face superior. Isso ocorre porque a face superior somente entrou em contato com o prato aquecido após seu fechamento, enquanto que a face inferior entrou em contato com o prato assim que o colchão foi posto para a prensagem.

Já no centro da chapa, a temperatura elevou-se mais lentamente que nas faces, permanecendo aproximadamente constante durante alguns minutos. Assim como nas faces, ocorreu rápido aumento da temperatura nos primeiros 100 segundos de prensagem. A seguir, um plateau, em que a temperatura permaneceu aproximadamente constante, correspondendo ao período de evaporação da umidade do colchão. Posteriormente, a temperatura volta a subir, porém, de forma mais lenta.

Uma vez que a temperatura mínima de cura para adesivos fenólicos é de aproximadamente $100{ }^{\circ} \mathrm{C}$, a Figura 1 evidencia que o tempo necessário para atingir essa temperatura (temperatura de aquecimento) foi de 150 segundos de prensagem. O painel precisa ainda permanecer na prensa por um período maior para promover a cura do adesivo.

\section{Influência da geometria dos flocos}

Observou-se que, independente do comprimento dos flocos, o início da elevação da temperatura ocorreu antes quando do emprego de flocos de maior espessura. A temperatura de ebulição d'água mantevese semelhante em todos os tratamentos analisados, correspondendo a aproximadamente $115^{\circ} \mathrm{C}$. Entretanto, apresentou-se levemente superior com o uso de flocos de menor espessura (Figura 2). 


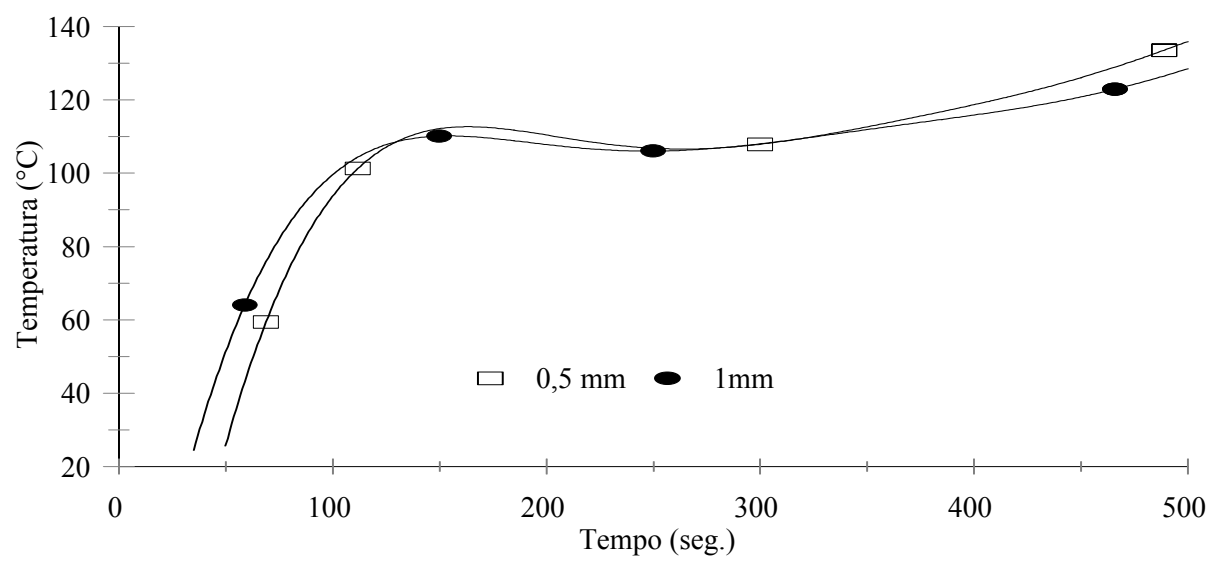

FIGURA 2: Comportamento da temperatura no miolo de chapas aglomeradas com relação ao tempo de prensagem para colchões formados por flocos de diferentes espessuras. Temperatura de prensagem igual a $180^{\circ} \mathrm{C}$.

FIGURE 2: Temperature behaviour at the core of particleboard for mat formed with flakes of different thicknesses. Pressing temperature of $180^{\circ} \mathrm{C}$.

O aumento inicial mais rápido da temperatura para flocos de maior espessura pode estar relacionado à maior permeabilidade dos colchões formados por estas partículas, favorecendo a transferência de calor por convecção (vapor d'água). A maior temperatura proporcionada pelo uso de flocos de menor espessura pode comprovar essa teoria. Flocos de maior espessura proporcionam maior quantidade de espaços vazios no colchão, favorecendo a saída do vapor d'água pelas bordas do colchão e, conseqüentemente, reduzindo a pressão de vapor. Segundo Haselein et al. (2002), partículas finas e flexíveis produzem menor quantidade de espaços vazios no interior das chapas. O grau de contato entre as partículas influi em diversas características das chapas aglomeradas.

Para as duas espessuras analisadas, o comprimento dos flocos aparentemente não influenciou a velocidade de transferência de calor, até atingir o plateau característico em que a temperatura manteve-se aproximadamente constante. Apesar da espessura dos flocos ter influência sobre a elevação inicial da temperatura, esse fator não influenciou significantemente no tempo de prensagem, uma vez que o tempo necessário para o centro do colchão atingir a temperatura de cura do adesivo foi de aproximadamente 100 segundos.

\section{Influência da temperatura de prensagem, tipo de partícula e teor de umidade do colchão}

$\mathrm{O}$ efeito do tipo de partícula e do teor de umidade do colchão mostrou-se mais pronunciado quando a prensagem ocorreu a $180^{\circ} \mathrm{C}$ (Figura 3 ).

O início do aumento da temperatura no centro de chapas produzidas com maior teor de umidade ocorreu antes quando comparadas às chapas produzidas com menor teor de umidade. Esse comportamento se mostrou independente do tipo de partícula. Entretanto, o tipo de partícula proporcionou variação no tempo necessário para a cura, sendo que os flocos de pinus atingiram temperaturas de cura após aproximadamente 100 segundos de prensagem e as partículas de eucalipto a aproximadamente 150 segundos (Figura 3).

Conforme descrito por Eleotério (2000), um maior período de tempo é necessário para a evaporação da umidade, quando se utiliza altos teores de umidade. Analisando o mesmo tipo de partícula, nota-se que, durante o período em que a temperatura dos colchões produzidos com altas umidades, mantêm-se constante, possivelmente pela manutenção da pressão de vapor, os colchões produzidos com baixa umidade já estão em fase secundária de elevação da temperatura. 


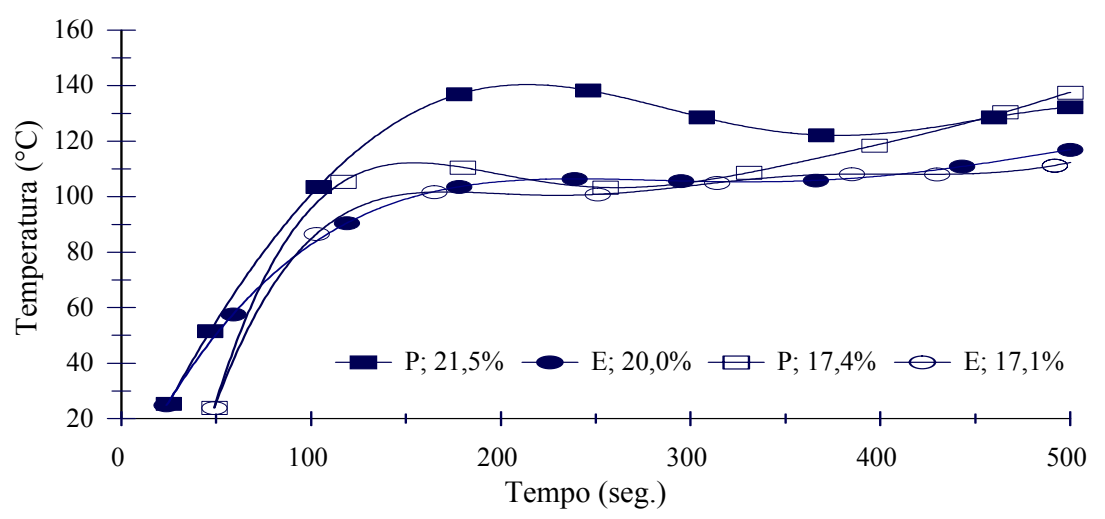

FIGURA 3: Comportamento da temperatura no miolo de chapas aglomeradas em função do tempo de prensagem a $180^{\circ} \mathrm{C}$, considerando os diferentes tipos de partículas e teores de umidade do colchão. Em que: $\mathrm{P}=$ flocos de pinus; $\mathrm{E}=$ partículas industriais de eucalipto.

FIGURE 3: Temperature behaviour at the core of particleboard pressed at $180^{\circ} \mathrm{C}$, for different types of particles and mat moisture content. $\mathrm{P}=$ pine flakes; $\mathrm{E}=$ eucalypt particles.

A Figura 4 mostra a influência do teor de umidade do colchão e temperatura de prensagem sobre a elevação da temperatura no miolo das chapas aglomeradas.

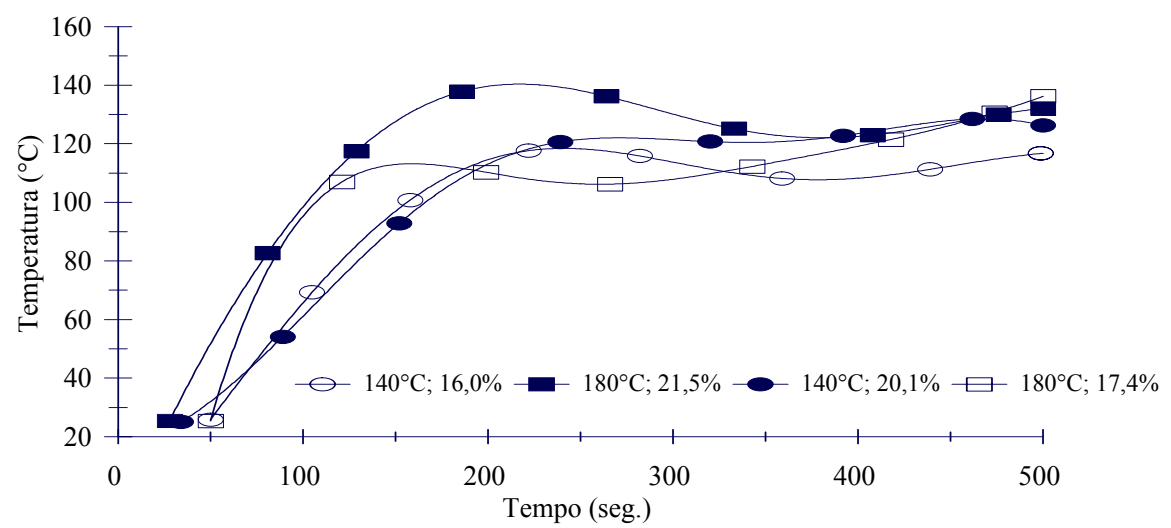

FIGURA 4: Comportamento da temperatura no miolo de chapas aglomeradas em função do tempo de prensagem para colchões formados por flocos de pinus, considerando as diferentes temperaturas de prensagem e teores de umidade do colchão.

FIGURE 4: Temperature behavior at board core for mat formed with pine flakes, considering different pressing temperatures and mat moisture content.

Da mesma forma que observado na Figura 3, o teor de umidade do colchão foi decisivo para o início da elevação da temperatura. Entretanto, a temperatura de cura do adesivo foi atingido anteriormente quando utilizado a maior temperatura de prensagem (Figura 4). Conforme descrito por Pichelin et al. (2001), esse comportamento se deve ao maior gradiente de calor produzido entre as faces e o centro do colchão.

A influência da espécie da madeira empregada não pode ser analisada de modo satisfatório, uma vez que apresentavam diferentes geometrias das partículas.

\section{CONCLUSÕES}

Os gráficos da elevação da temperatura com relação ao tempo de prensagem em painéis de madeira aglomerada apresentaram comportamento típico: rápido aumento da temperatura nos primeiros momentos de prensagem, mantendo-se um plateau possivelmente após atingir a temperatura de ebulição da água, e novo aumento gradual da temperatura após perda de grande parte da umidade do colchão.

A variação da geometria dos flocos de pinus proporcionou pouca alteração na temperatura de plateau, mantendo-se em torno de $115^{\circ} \mathrm{C}$. Colchões formados por flocos de maior espessura apresentaram elevação mais rápida de temperatura no miolo. 
O principal fator que influenciou no aumento inicial da temperatura assim como na temperatura no miolo dos painéis aglomerados foi o teor de umidade do colchão.

\section{AGRADECIMENTO} dos ensaios.

A SETA S.A. pelo fornecimento de adesivo e partículas de madeira de eucalipto para a realização

\section{REFERÊNCIA BIBLIOGRÁFICA}

ALBUQUERQUE, C.E.C. Otimização na produção de painéis. Revista da Madeira, p. 50-51, 2003. Edição especial

BOLTON, A.J.; HUMPHREY, P.E.; KAVVOURAS, P.K. The hot pressing of dry-formed wood-based composites. Part III. Predicted vapour pressure and temperature variation with times, compared with experimental date for laboratory boards. Holtzforshung, v.43, n.4, p.265-274, 1989.

CALEGARI, L; HASELEIN, C.R.; HILLIG, E.; SANTINI, E.J. Elevação da temperatura durante a prensagem de painéis aglomerados colados com tanino-fenol-formaldeído. In: CONGRESSO FLORESTAL ESTADUAL DO RIO GRANDE DO SUL, 8., 2000, Nova Prata-RS. Anais... Santa Maria: UFSM, 2000. p. 646-650.

ELEOTÉRIO, J.R. Propriedades físicas e mecânicas de painéis MDF de diferentes densidades e teores de resina. 2000. 121 f. Dissertação (Mestrado em Engenharia Florestal) - Escola Superior de Agricultura "Luiz de Queiroz", Piracicaba, 2000.

GARCÍA, P.J.; AVRAMIDIS, S.; LAM, F. Internal temperature and pressure responses to flake alignment during hotpressing. Holz als Roh und Werkstoff, v. 59, n. 4, p.272-275, 2001.

HASELEIN, C. R.; CALEGARI, L.; BARROS, M.V.; HACK, C.; HILlIG, E.; PAULESKI, D.T.; POZZERA, F. Resistência mecânica e à umidade de painéis aglomerados com partículas de madeira de diferentes dimensões. Ciência Florestal, v.12, n.2, p. 127-134, 2002.

KLOPFENSTEIN Jr., R. Software linearization of a thermocouple. Sensors Wordlink, 1997. 7p.

PICHELIN, F.; PIZZI, A.; FRÜHWALD, A.; TRIBOULOT, P. Exterior OSB preparation technology at high moisture content - Part 1: Transfer mechanisms and pressing parameters. Holz als Roh und Werkstoff, v. 59, n. 4, p.256-265, 2001.

STEFFEN, A.; HASS, G.; RAPP, A.; HUMPHREY, P.; THÖMEN, H. Temperature and gas pressure in MDF-mats during industrial continuous hot pressing. Holz als Roh und Werkstoff, v. 57, n. 2, p.154-155, 1999.

SULEIMAN, B.M.; LARFELDT, J.; LECKNER, B.; GUSTAVSSON, M. Thermal conductivity of wood. Wood Science and Technology, v.33, n.6, p.465-473, 1999.

WILCOX, H. Interrelationship of temperature, pressure, and pressing time in the production of hardboard from Douglas-Fir fiber: The effects of these variables on hardboard properties. Tappi, v.36, n.2, p.89-94, 1953.

ZOMBORI, B. G. Modeling the transient effects during the hot-pressing of wood-based composites. Tese (Ph.D.) Faculty of the Virginia Polytechnic Institute and State University, Blacksburg, Virginia, 2001. 